\title{
FUNCIONES DISCURSIVAS DE LAS ORACIONES EXISTENCIALES EN ESPAÑOL*
}

\author{
AXEL HERNÁNDEZ DÍAZ \\ Universidad Nacional Autónoma de México \\ hernandez.axel@gmail.com
}

RESUMEN

En algunas oraciones existenciales del español se observa cierta alternancia entre el carácter definido o indefinido de la frase nominal referida a la entidad existente. El verbo existencial prototípico haber, en contraste con otros existenciales, difícilmente participa de esta cualidad, a partir de lo que se observa una función discursiva presentativa específica de este verbo, la de introducir preponderantemente entidades nuevas en el discurso, función que lo distingue en términos semánticos y pragmáticos del resto de los verbos existenciales. En este trabajo se ofrece una explicación sobre las diferencias que subyacen a la alternancia de entidades existentes definidas o indefinidas en oraciones existenciales en relación con los conceptos tópico y foco. El análisis se basa en un corpus diacrónico constituido por estructuras pertenecientes al periodo comprendido entre los siglos XIII y XX.

PALABRAS CLAVE: verbos existencials; funciones discursives; oraciones presentativas; foco; tópico.

\section{DISCOURSE FUNCTIONS OF EXISTENTIAL SENTENCES IN SPANISH}

\section{ABSTRACT}

Some existential sentences in Spanish show alternation between definite and indefinite noun phrases (NP) as existential entities. The prototypical existential haber, in opposition to other existential verbs, hardly shows this quality. Based on their features, it is possible to identify a specific presentational function of haber: to introduce brand-new entities in discourse, showing a different discourse function to other existential verbs. This paper gives an account of semantic and pragmatic characteristics of haber through the alternation of definite and indefinite NP as existential entities as brand-new information or partial-new information, topic and focus. The analysis was made on a diachronic corpus from the XIIIth to the XXth centuries.

KEY WORDS: existential verbs; discourse funcions; presentational sentences; there constructions; focus; topic.

\section{INTRODUCCIÓN}

Una de las propiedades sintáctico-semánticas de las oraciones existenciales que las distinguen de otras construcciones es el carácter indefinido de la entidad existente (EE), elemento que desempeña la función de sujeto sintáctico de los verbos existenciales, con excepción de haber en la lengua española, como se advierte en los ejemplos de (1a) y (1b), respectivamente.

\footnotetext{
* El desarrollo de este artículo fue posible gracias al apoyo brindado al proyecto PE 400613 de la DGAPA de la UNAM durante 2013. Agradezco las sugerencias y los comentarios hechos por dos dictaminadores anónimos.
} 
(1) a. Et estaua y de cerca un mont; e parescien en somo de la cabeça del unas matas ralas (GEII, 426.40b)

permitido es, quando estrema neçesidad ocurre en los reynos \& tierras, como es ésta en que agora estáys, que se tome no sólo la plata, mas los bienes y rentas de las iglesias, y de las cosas sagradas (CRC, 144.25)

existen ciertos contenidos en los convenios de coalición en que para su determinación se toma en cuenta al número total de partidos políticos coaligados y su identidad (Sentencia, 68)

b. Que quando nasce ella nasce él, y quando él, ella. Ninguna cosa ay criada al mundo superflua ni que con acordada razón no proveyesse della natura (Celestina, VII.203) le han dicho el que les escriba para consuelo en las congojas que padece, procurando hazerlo a escondidas, porque no se siguiera el que supieran y leyeran sus trabajos y huviera otras pesadumbres (DLNE, 1747, 227.552)

No sé por qué se dan como fecha y año de su fallecimiento el 31 de diciembre y 1922, respectivamente, cuando no hubo testigos (Marías, 219)

Se suele afirmar que las EE se caracterizan por ser mayoritariamente indefinidas, desconocidas o no familares para el oyente (Christophersen 1939: 72, Lyons 1999: 3), debido a que la función informativa básica de las oraciones existenciales es introducir información en el discurso. También se ha dicho que son oraciones presentativas que, en términos funcionales, introducen el referente de una frase nominal en el universo discursivo y que los verbos con los que se expresan sirven para afirmar esta aparición (Rigau 1994, Suñer 1982: 1). Sin embargo, considero que es preciso hacer ciertas consideraciones al respecto pues, a mi modo de ver, no todas las oraciones existenciales son presentativas en el mismo sentido, dado que no siempre introducen referentes nuevos o desconocidos en el discurso.

El objetivo de este trabajo es dar una explicación sobre las diferencias semánticas y pragmáticas que subyacen a la alternancia de EE definidas o indefinidas en oraciones existenciales construidas con diversos verbos, pues creo que sus funciones discursivas no siempre son iguales y que es necesario hacer una subclasificación de estas oraciones considerando el valor topical o focal de las entidades introducidas mediante estos predicados.

\subsection{Hipótesis}

La hipótesis es que la presencia de EE definidas puede explicarse a partir de los conceptos nuevo para el oyente y nuevo en el discurso y al hecho de que, con frecuencia, la $\mathrm{EE}$, una parte de ella, un todo mayor a ella o un todo al que pertenece se ha mencionado previamente, razón por la cual es impreciso afirmar que la función de las oraciones existenciales es exclusivamente la de introducir entidades nuevas o totalmente nuevas en el discurso, en términos de Prince (1981), como se ha dicho, puesto que también sirven para introducir entidades parcialmente nuevas, concepto a mi modo de ver más adecuado para definir y delimitar una de las funciones discursivas que estas oraciones 
cumplen: presentar información nueva solo en ciertos aspectos con valor topical $y$ no focal en el contexto discursivo.

En cualquiera de los casos, ya sea que se trate de información totalmente nueva o no, las oraciones existenciales desempeñan una función presentativa. Al introducir entidades no solo totalmente nuevas sino también parcialmente nuevas, presentan ciertas variantes en su manifestación formal, específicamente en la manifestación formal de la $\mathrm{EE}$, en sus características sintácticas o en las cualidades de las oraciones que le anteceden o que van pospuestas a ella.

\subsection{El corpus}

El trabajo está basado en el análisis de un corpus conformado por 1.274 oraciones existenciales, pertenecientes al periodo comprendido entre los siglos XIII y XX. La muestra se hizo atendiendo a parámetros diacrónicos con el objetivo de identificar cambios, o al menos variación, en el comportamiento sintáctico o semántico de los constituyentes de las oraciones estudiadas, considerando que el verbo existencial más frecuente en español, haber, se usó en español antiguo como verbo de posesión (2a) (Hernández Díaz 2006a), sentido desde el que se desplazó al ámbito de la existencia en contextos ambiguos entre los dos valores (2b) (Hernández Díaz 2006a, 2007a y 2007b). La selección diacrónica de la muestra se hizo también teniendo en cuenta que, durante el mismo periodo, haber sirvió además como auxiliar en perífrasis de obligación (2c) y se gramaticalizó en la formación del futuro y del condicional (2d) (Company 2006), por un lado, y en la creación de los tiempos compuestos (2e), por otro (Romani 2006).

(2) a. Por mis fijas que m'dexaron yo non he desonor, / ca vos las casastes, rrey, sabredes que fer oy (Cid, v. 3149)

b. Nobleza de coraçón auye en él muy grande para desdennar e despreciar las cosas malas e viles e de pagarse de onrrar las nobles (Setenario, 11.19)

c. Et puesto qu'el león non me pensase mal, usando con él los malos consejeros, avríalos de escuchar et fazer por ellos (Calila e Dimna, 162)

d. Martin Antolinez, sodes ardida lança! / Si yo uibo, doblar uos he la soldada (Cid, v. 80)

e. otrogol que casarie con el, mas rogol que non dixiesse que lo auie acabado fasta que los otros ouiessen cerca dacabadas sus obras (Crónica general, 12a)

Así, con base en los antecedentes sintácticos y semánticos descritos, partimos de la suposición de que la documentación histórica quizá haría evidente algún cambio en las oraciones existenciales o que al menos sería importante estudiar su comportamiento a través del tiempo. Como veremos en el apartado siguiente, el desarrollo histórico de la clase verbal tiene un comportamiento consistente y homogéneo, en tanto que no hay quiebres considerables o reconfiguraciones sintácticas o semánticas comparables al cambio de haber de la posesión a la existencia o al ámbito de la auxiliaridad; en 
todo caso, lo que sí se documenta es un reajuste de la clase en términos de frecuencia y de especialización semántica y pragmática, según veremos.

Dado que no es el objetivo de este trabajo abarcar el comportamiento histórico de haber en su totalidad, sino solo analizar algunos rasgos semánticos y pragmáticos de su sentido existencial en oposición con el de otros verbos existenciales, no han sido considerados en el corpus sus usos posesivos ni tampoco sus usos como auxiliar; de tal manera, quedan fuera de la muestra construcciones como las de (2), incisos a), c), d) y e); no así las existenciales como la de (2b). Tampoco se consideraron para este trabajo casos como Tres días ha que sodes en mi poder (CORDE, s. v. ha, Cuento muy fermoso de Otas de Roma, España, c. 1300), en donde el verbo rige un complemento temporal y su lectura existencial no es muy clara. ${ }^{1}$

Distribucionalmente, se documentaron 767 construcciones con el verbo haber y 507 con otros verbos con los que también se expresa la existencia, que cumplen con la función discursiva de introducir entidades en el discurso aunque no sean prototípicamente existenciales. Del total de ocurrencias, el $61 \%$ corresponde al verbo haber y el $39 \%$ restante a los treinta y cuatro verbos siguientes, ordenados alfabéticamente: acaecer, acontecer, andar, aparecer, asentar, asomarse, comenzar, constar, crecer, darse, desatarse, discurrir, durar, encontrarse, estallar, estar, existir, figurar, hacerse, hallarse, ocurrir, pasar, permanecer, prevalecer, quedar, residir, resultar, salir, seguir, ser, suceder, transcurrir, venir y yacer. Para seleccionar las oraciones, fue preciso que tuvieran las características siguientes: independientemente del predicado con el que se construyan, están formadas por el verbo y la entidad existente de la cual se predica la existencia, como elementos básicos de la oración, y pueden o no incluir uno o varios complementos circunstanciales cuya función es ubicar la EE en coordenadas espaciales, temporales o en ambas.

La documentación se hizo, en cada uno de los textos del corpus, en un universo cercano a las 60.000 palabras que aproximadamente tiene el Calila $e$ Dimna, primer texto fichado que se tomó como referencia cuantitativa. Aquellos cuya extensión es cercana a las 60.000 palabras se ficharon completos y de los restantes seleccioné una muestra equivalente a dicha cantidad. El cuadro 1

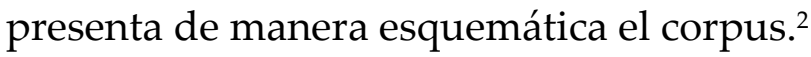

\footnotetext{
${ }^{1}$ En estos casos tampoco está muy claro si se trata del verbo haber o de hacer, de manera que considero que estas construcciones merecen un estudio pormenorizado independiente.

2 Para la información completa y detallada de los títulos y las ediciones utilizadas, véase el §6 al final.
} 


\begin{tabular}{|c|l|}
\hline \multirow{3}{*}{ XIII } & $\begin{array}{l}\text { Calila e Dimna } \\
\text { General estoria } \\
\text { Documentos lingüísticos de España }\end{array}$ \\
\hline \multirow{3}{*}{ XV-XVI } & $\begin{array}{l}\text { La Celestina } \\
\text { Crónica de los Reyes Católicos } \\
\text { Documentos lingüísticos de la Nueva España }\end{array}$ \\
\hline XVIII & $\begin{array}{l}\text { Obras en prosa (M. G. de Jovellanos) } \\
\text { Vida, ascendencia, nacimiento, crianza y aventuras (D. de Torres y } \\
\text { Villarroel) } \\
\text { Documentos lingüísticos de la Nueva España }\end{array}$ \\
\hline XX & $\begin{array}{l}\text { Negra espalda del tiempo (Javier Marías) } \\
\text { “Vislumbres de la India" (Octavio Paz) } \\
\text { "Sentencia y votos de minoría particulares y aclaratorios...." }\end{array}$ \\
\hline
\end{tabular}

CUADRO 1. Corpus

Además de este primer apartado, el trabajo está dividido en las siguientes secciones: en $\S 2$ se exponen las peculiaridades sintácticas y semánticas de las oraciones existenciales y se caracterizan en términos diacrónicos y sincrónicos; en $\S 3$ se discute cuáles son las funciones discursivas de las construcciones analizadas a partir de los resultados del corpus; en $\$ 4$ se propone una clasificación de las oraciones existenciales a partir de sus funciones informativas; en §5 se exponen las conclusiones y, por último, en §6 se ofrece la información bibliográfica tanto del corpus como de los textos citados.

\section{Peculiaridades de las oraciones existenciales. Caracterización DIACRÓNICA}

El carácter indefinido de las EE, único argumento de estos predicados, se suma a otras peculiaridades sintácticas y semánticas de estas construcciones: 1) son oraciones en las que el verbo aparece en primera posición o bien antepuesto a su único argumento (Hay una caja de lápices sobre el escritorio; En México existen muchos casos de maltrato), de modo que no se ajustan al orden básico S-V-O; 2) si bien en casi todos los casos -con excepción del verbo haber- la EE es el sujeto sintáctico puesto que concuerda con el verbo en número y persona, no satisface las cualidades semánticas prototípicas de los sujetos porque los verbos existenciales no enuncian acciones ni actividades sino que pertenecen a la clase de los verbos estativos; 3 ) en términos informativos, dado que la EE es el único argumento verbal, es difícil establecer una dicotomía entre una parte de la oración que figure como la información conocida, en contraposición con otra que funcione como información nueva en el discurso.

Resulta problemático también identificar las EE como el sujeto sintáctico de las oraciones debido a su caracterización semántica (3), ya sea que se trate de verbos existenciales en los que la concordancia entre el verbo y su único argumento es gramaticalmente correcta (3a) o bien que se trate de una concordancia agramatical, como ocurre con el verbo haber ( $3 b)$ (véase más abajo la nota 3). 
(3) a. Señor, sepas que las naturalezas de las criaturas son de muchas maneras, et non es ninguna cosa de quantas Dio[s] crió en el mundo de las que andan en quatro pies et en dos pies o que buelan con alas, más santa ni más mejor que el omne. Et en los omnes ha buenos et malos (Calila, 317)

$\mathrm{Y}$ un dia de aquella semana en que acontecio esta concurrencia, que fue martes, la llevó a cassa de un yndio que estava en consorsio de otro hermano sullo (DLNE, 1750, 233.569)

En tu novela aparecerán lugares o instituciones reales, ¿no? (Marías, 69)

b. A mí se me identifica con canciones más reflexivas y tristes, pero en mi nuevo disco van a haber canciones más alegres (CREA, s. v. van a haber, periódico, Perú)

La gente me cree, y en México tenemos escasez de líderes naturales. Los pocos que habemos somos combatidos por múltiples intereses (CREA, s. v. habemos, periódico, México)

Con base en las características citadas, podemos afirmar que el único argumento de los verbos existenciales dista de la caracterización de los sujetos prototípicos: grupos nominales o equivalentes antepuestos al verbo, que desempeñan la función informativa de tema, por lo que han de estar suficientemente identificados (RAE 2009: §33.1i). Los grupos nominales formados por nombres comunes sin determinante o modificador, llamados escuetos en tanto que no recuperan referentes previamente introducidos en el discurso (RAE 2009: §15.9e), no ejercen en español la función de sujeto preverbal sino en algunos contextos restringidos. Así, son agramaticales oraciones como ${ }^{*}$ Niños disfrutaban fiestas, ${ }^{*}$ Fútbol es el deporte preferido por los jóvenes. En las oraciones existenciales, sin embargo, el hecho de que el sujeto aparezca en posición posverbal posibilita que las EE sean mayoritariamente escuetas (4a) y que, por el contrario, lo marcado en términos formales y discursivos sea la presencia de nominales definidos (4b), esto es, que se refieran a entidades familiares e identificables por hablante y oyente (Christophersen 1939: 72), o expandidos, es decir, con modificadores pospuestos que los determinen $(4 \mathrm{c})$.

(4) a. vamos entramos, y si en esso se pone, spantémosla de manera que le pese; que sobre dinero no ay amistad (Celestina, XII.268)

se tiene por çierto ay yslas çerca (DLNE, 1525, 1.34)

CELESTINA. Paz sea en esta casa

LUCRECIA. Celestina, madre, seas bienvenida (Celestina, IV.151)

b. declaramos la neçessidad mui grande que en estas partes ay de que de nuevo vengan de esos reinos de España cantidad de religiosos (DLNE, 1564, 31.150)

Dase quenta a vuestra majestad de todo esto, para que vuestra majestad, supuesto esto y teniendo entendido la voluntad que ay de parte de la orden para el servicjo de Nuestro Señor y de vuestra majestad (DLNE, 1563, 29.147)

c. Acaesçió en aquellos días, que don Juan de Acuña, duque de Valencia, el qual estaua a la obediençia del rey de Portogal, estando en vna torre de la su villa de Valençia, cayó della e murió luego (CRC, 134.3)

enbió su mensagero al rey de Portogal, a le hacer saber en cómo sería necesario que se viesen en uno para platicar algunas materias que al servicio de Dios e al bien de sus reynos por estonces ocurrían (CRC, 46.28) 
Con todo, en las oraciones existenciales se observa cierta alternancia entre el carácter definido o indefinido de la EE, entendiendo por definidos referentes conocidos o familiares para hablante y oyente y por indefinidos lo contrario. El verbo existencial prototípico en español, haber, en contraste con otros verbos con los que también se expresa la existencia, participa con menor frecuencia de esta cualidad. Podemos afirmar que presenta ciertas restricciones con respecto a la aparición de EE definidas como único argumento (Hernández Díaz 2007a). Esta baja frecuencia se debe, según creo, a que el verbo haber tiene una función presentativa específica en el discurso, que lo distingue del resto de los predicados con los que se puede expresar la existencia.

Las construcciones que contrastan con el supuesto teórico de que la EE debe ser indefinida, puesto que introduce información nueva en el discurso, tienen su explicación en dos hechos: el primero es que la definitud no se da únicamente en función de una marca léxica sino también en función de las estructuras que acompañan a las oraciones y el segundo es que la marca léxica de definitud no necesariamente se corresponde con el carácter específico propio de las EE.

Dijimos antes, en el apartado anterior, que el comportamiento sintáctico y semántico de las oraciones estudiadas es bastante homogéneo en perspectiva diacrónica, lo que puede sorprender luego del alto grado de polisemia y multifuncionalidad del verbo haber en el español, mostrados en (2). Pero, una vez que el valor existencial se consolida en el verbo haber, alrededor del siglo $\mathrm{XV}$, luego de que desaparece la concordancia entre el sujeto poseedor y el verbo para dar paso a los usos impersonales de haber y de haberse gramaticalizado también como auxiliar, las estructuras documentadas tanto con este verbo como con los demás predicados de la clase se ajustan a las características sintácticas y semánticas descritas en este apartado.

Así, se trata de oraciones compuestas por el verbo y la EE más uno o varios complementos circunstanciales que pueden o no aparecer de manera explícita en la oración. En términos semánticos, las oraciones afirman o niegan la existencia de la EE. Según sus propiedades sintácticas y semánticas, pueden ser descritas como construcciones inacusativas, dado que los sujetos muestran rasgos semánticos opuestos a los sujetos prototípicos: no son agentes y con mucha frecuencia se refieren a objetos o a entidades abstractas. En el caso de haber, además, la EE no es el sujeto sintáctico de la oración dada la naturaleza impersonal de este predicado. ${ }^{3}$

\footnotetext{
${ }^{3}$ Es bien sabido y está documentado que existe una fuerte tendencia a la generación de concordancia entre el verbo haber impersonal y la entidad existente (habian muchas preguntas entre los asistentes; hubieron varias críticas a los proyectos; habemos muchos indecisos) (cfr. Hernández Díaz 2004, Hernández Díaz 2006b, Bentivoglio 1993, Bentivoglio y Sedano 1989). Este fenómeno refuerza la caracterización de estas estructuras como inacusativas, pues en ellas el hablante ha reanalizado la EE como el sujeto sintáctico de las oraciones, de manera que le atribuye rasgos semánticos que lo asemejan al sujeto más que al objeto.
} 
Como se observa en el cuadro 2, el predominio de haber sobre el resto de los verbos existenciales es evidente en todas las épocas. La diferencia máxima a favor de haber, predicado central o prototípico de la clase, se ubica en el corte correspondiente a los siglos XV-XVI, etapa en la que al mismo tiempo se observa un decremento importantísimo en el uso de $\operatorname{ser}(36 \%>3 \%)$ y un leve incremento en el caso de estar $(11 \%>17 \%)$, cambio ocurrido en el ámbito de los verbos existenciales que ocasionó algunos reajustes internos en la clase verbal.

\begin{tabular}{|c|c|c|c|c|c|}
\hline & haber & ser & estar & existir & otros \\
\hline XIII & $49 \%(146 / 300)$ & $36 \%(108 / 33)$ & $11 \%(35 / 300)$ & - & $4 \%(11 / 300)$ \\
\hline XV-XVI & $71 \%(266 / 375)$ & $3 \%(13 / 375)$ & $17 \%(64 / 375)$ & - & $9 \%(32 / 375)$ \\
\hline XVIII & $59 \%(139 / 236)$ & $2 \%(4 / 236)$ & $9 \%(21 / 236)$ & $2 \%(6 / 236)$ & $28 \%(66 / 236)$ \\
\hline XX & $60 \%(216 / 363)$ & $2 \%(7 / 363)$ & $2 \%(7 / 363)$ & $18 \%(64 / 363)$ & $18 \%(69 / 363)$ \\
\hline Total & $60 \%(767 / 1274)$ & $10 \%(132 / 1274)$ & $10 \%(127 / 1274)$ & $5 \%(70 / 1274)$ & $15 \%(178 / 1274)$ \\
\hline
\end{tabular}

CUADRO 2. Frecuencia de uso de los verbos existenciales

Se observa también en el cuadro 2 que existir, contrariamente a lo que pudiera esperarse dado que es el predicado que da nombre a las estructuras estudiadas, se documenta por primera vez en el siglo XVIII. Corroboran los datos del corpus algunos diccionarios (RAE 1732/1984: s.v. existir, Corominas 1980: s.v. existir, De Miguel 189711/2003: s.v. existir) y el CORDE (http://corpus.rae.es/cordenet.html): s.v. existir.

La columna al extremo derecho del cuadro, con el encabezado otros, agrupa los 31 predicados de menor frecuencia en el corpus, que pueden ser caracterizados como los márgenes categoriales de la clase: acaecer, acontecer, andar, aparecer, asentar, asomarse, comenzar, constar, crecer, darse, desatarse, discurrir, durar, encontrarse, estallar, figurar, hacerse, hallarse, ocurrir, pasar, permanecer, prevalecer, quedar, residir, resultar, salir, seguir, suceder, transcurrir, venir y yacer. Debido a la baja aparición de estos verbos, decidí considerarlos en un solo grupo para el conteo, con la intención de que los porcentajes de uso resultantes fueran significativos en términos cuantitativos. A pesar de su bajo registro (178 casos en total), hay un incremento diacrónico interesante en la frecuencia de los verbos que integran el grupo, $4 \%>9 \%>28 \%>18 \%$, que hace evidente que la clase que forman se amplía y se diversifica, sobre todo, entre los siglos XV y XX.

En general, se puede afirmar que las construcciones existenciales han experimentado ligeros ajustes en distintos aspectos que, a mi modo de ver, no llegan a ser sustanciales, en tanto que no representan un quiebre, sino que pueden describirse como cambios internos en términos de frecuencia y de especialización de algunas formas para desempeñar funciones comunicativas 
que aportan matices semánticos o pragmáticos específicos a las oraciones, tales como los que se analizan en este artículo.

En relación con la lengua latina, hubo un cambio importante en cuanto a la relevancia discursiva que adquieren la EE y el evento existencial en sí mismo para seleccionar el verbo que mejor se ajusta a las condiciones que lo enmarcan. Se advierten, a partir de ello, modificaciones en la conformación estructural de los enunciados y en el carácter argumental de los verbos. Finalmente, la semántica de las entidades involucradas en los sucesos, la EE y los CC, y de las expresiones en sí varía diacrónicamente en los siguientes aspectos: 1) la integración de la clase verbal, 2) los procesos de gramaticalización y reanálisis mediante los cuales algunos verbos se integraron a la clase al modificar su conformación sintáctica y semántica, 3) la gramaticalización del eje de la locación con respecto a la existencia en la formación de los predicados, 4) la relevancia discursiva de la EE y del evento para la selección del verbo. Si bien todos ellos son interesantes, en este artículo nos concentramos únicamente en el inciso cuatro.

A partir de estos aspectos, se identifican dos grandes tendencias: 1) una tendencia a la diversificación sintáctico-semántica de las construcciones y 2) una tendencia a la especialización en el señalamiento de los aspectos pragmáticos que envuelven los eventos expresados por las construcciones.

\section{FUNCIONES DISCURSIVAS DE LAS ORACIONES EXISTENCIALES}

Como es sabido, se afirma que la función discursiva primoridal de las oraciones existenciales es la de introducir entidades nuevas en el discurso, a partir de lo que se explican el carácter frecuentemente indefinido de la EE y el orden marcado de los constituyentes [VERBO-EE], pues ambas cualidades se relacionan con el peso informativo de los mismos. En tanto que la EE se considera información nueva para el oyente, se ha dicho que el verbo funciona como punto de referencia para ubicarla, por lo que puede aparecer en primer lugar de la oración (5a) o al menos antepuesto a su argumento (5b).

\section{(5) a. Hay helado en el refrigerador \\ b. En el refrigerador hay helado}

Con base en las características de estas estructuras, en efecto las más frecuentes, se afirma que las frases nominales que funcionan como argumento verbal de los existenciales se distinguen por ser frases nominales escuetas, puesto que carecen de determinantes antepuestos y también de modificación pospuesta dado su carácter de información nueva en el discurso y dada la función presentativa de la oración en la que aparecen.

Esta afirmación deja de lado el hecho de que las oraciones existenciales sirven también para hablar de entidades conocidas por hablante y oyente, al menos en algún sentido, a propósito de las cuales se añaden características o cualidades desconocidas hasta ese momento por el interlocutor, de manera que 
es posible que las EE hayan sido previamente mencionadas en el discurso y que ello no impida que aparezcan luego en una oración existencial.

En (6), por ejemplo, las EE aparecen por primera vez en el discurso en las oraciones existenciales y constituyen, por lo tanto, información totalmente nueva en el contexto. En ellas, el verbo aparece antepuesto a la entidad y, a mi modo de ver, sirve como una marca que indica que enseguida aparecerá información nueva: dotze figueras y çinco perales, en el primer ejemplo, y un arco de piedra, en el segundo.

(6) uos entrego diez tafullas de real que son ante la puerta del real que fue de Garçia Ioffre, en que ha dotze figueras y çinco perales (DLE, 1293, 371. 491)

Apareció un arco de piedra, plantado en un muelle y rematado por cuatro torrecillas en forma de piña (Paz, 360)

En (7), por el contrario, en oraciones previas a la existencial que nos interesa se habla ya de doce mil homes a caballo, de entre los cuales, información parcialmente nueva, avía pocos caualleros que no fuesen encubertados.

(7) E todas aquellas gentes fueron repartidas por sus capitanes en treinta e cinco batallas, en que había doce mil homes a caballo; de los quales eran cuatro mill onbres de armas, do avía pocos caualleros que no fuesen encubertados (CRC, 134.25)

Si bien se ha afirmado que la función informativa de las oraciones existenciales es presentar entidades nuevas en el universo discursivo, las propiedades de muchas de estas construcciones no se corresponden con dicha caracterización, por lo que creo pertinente discutir y mostrar que esto no siempre es así, sino que, además de presentar información nueva en el discurso, las oraciones existenciales desempeñan también otras funciones informativas, que justifican que las EE no siempre sean nominales escuetos, sino que pueden aparecer con determinantes antepuestos o bien pueden estar expandidos.

A diferencia de lo que ocurre para el español, existe bibliografía considerable sobre el tema para otras lenguas. Algunos autores (Abbott 1992 y 1997, Birner y Ward 1993, Birner 2006, Breivik 1983, 1997 y 2003, Davidse 1999, García Romero 2003, Hannay 1985, Laca 1996, Lumsden 1988, Milsark 1979) han dicho que si la función pragmática de las oraciones es la introducción de entidades nuevas, semánticamente serán indefinidas y formalmente llevarán modificadores de naturaleza indefinida o ausencia de modificación porque el oyente no tiene una referencia previa de ellas, sino que la construye en ese momento y justamente a partir de las propias oraciones existenciales, por lo que se espera que aparezcan definidas o especificadas en oraciones subsecuentes a la existencial. No obstante, hay algunas excepciones para las que han sido propuestas varias explicaciones basadas en las inferencias que hablante y oyente realizan con respecto de entidades previamente mencionadas en el discurso, que luego se retoman referidas de otro modo (Abbott 1992 y 1997, Birner 2006, Prince 1981 y 1992). Para el catalán, además, se han hecho 
propuestas relacionadas con la alternancia de los verbos haver y ser en oraciones existenciales presentativas (Rigau 1994).

La discusión sobre el carácter definido que pueden tener algunas EE puede resolverse, a mi modo de ver, atendiendo al contexto específico en el que se producen las oraciones y las relaciones que establecen con el discurso previo. La ocurrencia de EE definidas puede explicarse a partir de la aplicación de un análisis informativo en los términos siguientes: nuevo para el oyente, nuevo en el discurso y además parcialmente nuevas en el discurso, distinción que explicaré más adelante.

Algunas teorías sobre las funciones pragmáticas de las oraciones existenciales en otras lenguas (Hannay 1985) señalan que estas no constituyen actos ilocutivos, puesto que no reflejan ninguna intención interactiva que el hablante pueda tener con respecto de su interlocutor. Las oraciones existenciales son solo actos presentativos $y$, por ello, lo esperado es que las entidades que introducen sean sobresalientes en el contexto. Hannay (1985: 175), sin embargo, considera que al menos en inglés es necesario establecer una distinción entre dos funciones discursivas esencialmente diferentes, puesto que no siempre la entidad presentada por el hablante es necesariamente la información más relevante en el contexto; así, propone una distinción entre los conceptos foco y presentativo, como dos funciones pragmáticas diferentes. A su vez, el autor divide la función presentativa en dos tipos:

Presentativa 1:

Referida a entidades que son presentadas por el hablante sin un fondo o contexto común entre hablante y oyente (ungrounded presentatives). Estas oraciones, en inglés, necesariamente llevan al inicio de la oración la forma there.

Presentativa 2:

Referida a entidades que son presentadas por el hablante en un fondo o contexto común con su oyente (grounded presentatives). En inglés, estas construcciones no llevan la forma there.

Es evidente que la distinción planteada por Hannay no puede establecerse en los mismo términos formales en español porque no existe la forma there del inglés, como una estructura desgastada y gramaticalizada caracterizadora de las oraciones existenciales (there is/are) (Breivik 1997, Hannay 1985: 173-175, Lyons 1975). ${ }^{4}$ Es necesario, entonces, acudir a criterios de tipo sintáctico y semántico que ayuden a definir el estatus informativo del enunciado y las diferencias que hay entre las distintas construcciones existenciales en español.

\footnotetext{
${ }^{4}$ Si bien la evolución diacrónica del adverbio latino ibi (ibi $\left.>i / y\right)$ que se gramaticalizó en el presente de indicativo de haber (ha i >hay), véase Hernández Díaz (2003), tiene ciertas similitudes con there, no puede emplearse para establecer una distinción entre las funciones informativas de los verbos existenciales.
} 


\section{Clasificación de las oraciones eXistenciales a PARTIR De SU FUNCIÓN INFORMATIVA}

Partiremos de que la función de las oraciones existenciales es presentar entidades, eventos o asuntos en el mundo discursivo, que pueden ser el foco de la predicación o no, es decir, el segmento que pone de relieve cierta información en el interior de un mensaje resaltado mediante distintas alternativas, concernientes a medios fónicos y sintácticos (RAE 2009: §40.4). Cuando no lo son, con mucha frecuencia han sido mencionadas previamente en el discurso categorías o conjuntos mayores, destacados en cursivas en los ejemplos de (8), que las incluyen como en (8a); que establecen con ellas diferentes tipos de relación, por ejemplo de parte-todo, como en (8b) o de subclases de una clase, como en (8c).

(8) a. algunos son a que Dios da buena andançia en su riqueza, et recabdan lo que quieren sin su alvedrío et sin ninguna obra. Et algunos son que se les acaba su buena andançia, que los guía Dios a ser envisos (Calila, 323)

Et entre los otros vasallos qu'él allí tenía avía dos lobos çervales (Calila, 125)

Sepan los qui agora son e los che an aseer cuemo io Gonzaluo Pedrez e Ferrant Pedrez, mio ermano [...] uendemos a uos Pedro Ordonnez \& a dona Jllana uuestra mugier un solar (DLE, 1222, 170.220)

en el fatídico Hotel Isabel sólo hay balcones en el primer y segundos pisos, no los hay en el cuarto (Marías, 252)

b. no existía ningún libro ni, al parecer, artículo sobre Gawsworth (Marías, 154)

En ellas se encuentran casi siempre cuentos de los viejos y eminentes maestros Shiel y Machen -King Felipe I y Archiduque de Redonda respectivamente- y algunos del propio discípulo y príncipe heredero bajo sus diferentes nombres. Hay uno de su compinche Lawrence Durrell (Marías, 171)

c. Connosçuda cosa sea a todos los que son cumo alos que son por uenir (DLE, 1225, 174.225)

Señor, sepas que las naturalezas de las criaturas son de muchas maneras, et non es ninguna cosa de quantas Dio[s] crió en el mundo de las que andan en quatro pies et en dos pies o que buelan con alas, más santa ni más mejor que el omne. Et en los omnes ha buenos et malos (Calila, 317)

son tan pocos de los que queda memoria o registro y hay tantos que se difuminan y despiden pronto como si la tierra careciera de tiempo para asistir a sus afanes y a sus fracasos o logros o hubiera urgencia por deshacer de sus alientos y de sus voluntades aún incipientes (Marías, 235)

En las oraciones existenciales, algunas veces las entidades presentadas, que hemos llamado aquí EE son el foco y otras no. Es a partir de la selección del verbo existencial, del contexto o bien de la sintaxis de las oraciones como puede establecerse una distinción entre las EE que funcionan como foco y las que no. Así, en (9a) las EE funcionan como foco dado que no han sido previamente mencionadas en el discurso y constituyen información totalmente nueva, a diferencia de las que se observan en (9b), donde las EE no parecen ser el foco de la predicación; por el contrario, son presentadas y situadas por el emisor en un fondo o contexto común con el receptor puesto que ya han sido directamente 
mencionadas o bien han sido previamente aludidas de manera indirecta, a partir de los elementos marcados en cursivas en los ejemplos: esta piedra, en el primer ejemplo; diez y ocho hermanos, en el segundo y partidos en el tercero.

(9) a. Et quando el ome vio que el ladrón avía vaziado el trigo en la sávana para se ir con ello, él dixo: - A esta cosa non ay sufrimiento, ca si se me va este ladrón con el trigo, allegárseme ha mayor la pobreza et fanbre (Calila, 97)

cada día ay hombres penados por mujeres y mujeres por hombres, y esto obra la natura y la natura ordenóla Dios (Celestina, IV.170)

dirás que adonde ay mayor entendimento ay menor fortuna y donde más discreción, allí es menor la fortuna (Celestina, I.125)

b. Parad mientes e non lo oluidedes, que esta piedra pongo yo aqui que sea por testimonio que oyestes uos todos los mandados e todas las palabras que el Sennor dixo (GEII, 119.4b)

Casóse con Manuela de Villarroel, y salimos de este matrimonio diez y ocho hermanos; y sólo estamos hoy en el mundo mis dos hermanas, Manuela y Josefa Torres, y yo que todavía estoy medio vivo (Villarroel, 64)

si en una coalición se encuentran integrados más de dos grupos o en este caso partidos, el hecho de que uno de los coaligados decida retirarse de la coalición, eso no implique (sic) que la coalición tenga que desaparecer, así lo expresa la siguiente tesis: 'coalicion. subsiste mientras existan dos partidos politicos (sic) nacionales que la formen (Sentencia, 67)

Por lo que respecta a haber, el verbo de uso más frecuente, la EE suele aparecer mayoritariamente pospuesta a él. En términos discursivos, sirve básica y especialmente para introducir entidades cuya función pragmática es ser foco mientras que el propio verbo funciona como tópico, es decir, como la información conocida o compartida entre hablante y oyente (Givón 1983a y b). Al utilizar haber, esencialmente se resalta o enfatiza que: la forma hay, habrá, hubo, etc., anuncia que aparecerá información nueva en el discurso. Así, el tópico es la existencia en sí misma, como información compartida que anuncia y resalta que la información que aparecerá enseguida es nueva y focal. Los ejemplos en (10) poseen dicha conformación informativa. El verbo haber se antepone a las EE y funciona como tópico a partir del cual se ubica y adquiere carácter relevante el foco de la predicación. En estos casos, según se advierte, la entidad no ha sido mencionada previamente.

(10) regnaua en Egipto un rey a que llamauan Vozeses, et maestre Godofre le dize Vesor; mas en esto del demudamiento de los nombres non ay fuerça segunt lenguas departidas, ca pueden los omnes auer assi los nombres segund sennas tierras (GEII, 114.19a)

No ay otra colación para mí sino tener tu cuerpo y belleza en mi poder (Celestina, XIX.324)

Y para esto, muy catholico señor, ay muchos inconvenjentes (DLNE, 1525, 1.43)

Yo confieso que ésta (sic) es una empresa superior a mis fuerzas. Si hubiese un hombre que reuniera en sí todos los conocimientos históricos y toda la doctrina legal [...] ese solo sería capaz de acometer y acabar tamaña empresa (Jovellanos, 99) 
El orden marcado para el español [VERBO-EE], frecuente en las oraciones construidas con haber, se explica entonces a partir de su función informativa. Por medio del desgaste semántico de haber como verbo pleno y por medio de un proceso de rutinización del uso de una estructura, $H A B E R-E E$, el verbo existencial prototípico se convierte en una forma desprovista de su semántica originalmente transitiva posesiva (Garachana 1994 y 1997, Hernández Díaz 2006a), en un recurso discursivo para anunciar que está por aparecer información nueva en el contexto. El verbo funciona también como lo que se ha llamado una forma de accesibilidad alta (Ariel 1988 y 1990: 1-30, Goldberg 1995, 2006: 9), es decir, como una estructura que se distingue en el contexto según que esté disponible o al alcance del receptor en algún nivel particular del discurso.

De los 35 verbos existenciales documentados en el corpus, haber es el que introduce en mayor número de ocasiones EE indefinidas, $86 \%$ en promedio durante los siglos considerados, mientras que el resto lo hace en una frecuencia bastante menor; por señalar un contraste, existir, introduce entidades indefinidas en promedio $61 \%$ de las veces en que aparece.

\begin{tabular}{|c|c|c|c|c|c|c|c||c|c|}
\hline \multicolumn{2}{|c|}{ haber } & \multicolumn{2}{c|}{ ser } & \multicolumn{2}{c|}{ estar } & \multicolumn{2}{c|}{ existir } & \multicolumn{2}{c|}{ otros } \\
\hline DEF & INDEF & DEF & INDEF & DEF & INDEF & DEF & INDEF & DEF & INDEF \\
\hline $14 \%$ & $86 \%$ & $66 \%$ & $34 \%$ & $50 \%$ & $50 \%$ & $39 \%$ & $61 \%$ & $64 \%$ & $36 \%$ \\
$(106 / 767)$ & $(661 / 767)$ & $(87 / 132)$ & $(45 / 132)$ & $(63 / 127)$ & $(64 / 127)$ & $(27 / 70)$ & $(43 / 70)$ & $(114 / 178)$ & $(64 / 178)$ \\
\hline
\end{tabular}

CUADRO 3. Entidad existente definida vs. indefinida ${ }^{5}$

Estos datos apoyan la afirmación acerca de que la función discursiva central de haber es introducir información nueva en el discurso y que otros verbos existenciales cumplen esa función, en menor medida. Una vez que se han introducido las EE indefinidas, estas suelen volverse específicas por medio de modificadores pospuestos, también llamados expansión, la cual además de colaborar en su delimitación, destaca su carácter focal. Si el propio verbo haber funciona como tópico cuando introduce EE indefinidas y estas últimas son el foco o la información nueva, ${ }^{6}$ al serlo, pueden tener una forma expandida, que bien

${ }^{5}$ En este cuadro, los resultados relativos a los cuatro verbos de mayor frecuencia en el corpus (haber, ser, estar y existir) aparecen en las cuatro primeras columnas, mientras que los datos correspondientes a los 31 restantes (acaecer, acontecer, andar, aparecer, asentar, asomarse, comenzar, constar, crecer, darse, desatarse, discurrir, durar, encontrarse, estallar, figurar, hacerse, hallarse, ocurrir, pasar, permanecer, prevalecer, quedar, residir, resultar, salir, seguir, suceder, transcurrir, venir y yacer) se agrupan en la columna otros, a la derecha, ya que representan una minoría en términos porcentuales. Han sido agrupados con la intención de que los resultados obtenidos sean numéricamente representativos.

${ }^{6}$ Este es uno de los factores que contribuyen con la generación de concordancia de número, habían, hubieron, van a haber, etc., y más aún con la de número y persona manifiesta en la forma habemos, puesto que el hablante reconoce el verbo existencial como la información topical, lo conocido -semejante a lo que ocurre con el sujeto- y la información que aparece pospuesta al verbo, es decir la entidad existente, funciona como el foco de la predicación. Me refiero a expresiones como hubieron fiestas durante toda la semana, habemos personas que no creemos en la 
puede manifestarse formalmente como complementos adnominales o como oraciones subordinadas que funcionan como modificadores o determinantes.

En los ejemplos de (11), puede apreciarse que las oraciones subordinadas destacadas en cursivas definen y especifican las EE; de no aparecer, estas tendrían una lectura inespecífica, cercana a la de los sustantivos genéricos y serían por lo menos informativamente anómalas o incluso agramaticales.

(11) ¡Mándase Dios que en la tierra donde yo soy naçiese tal fruta, comoquier que ay otras buenas frutas que cumplen asaz con que se pueden escusar los dátiles! (Calila, 303)

¿Si le sé, señora? No ay niño ni viejo en toda la cibdad que no le sepa; ¿avíale yo de ignorar? (Celestina, IV.152)

Agragáronse a su opinión y su cortesanía los demás médicos y no hubo achacoso, doliente ni postrado que solicitase mi visita (Villarroel, 168)

Krishna no propone realmente una nueva solución sino que traza un puente: hay acciones que, si son realizadas con verdadero desprendimiento, equivalen al acto del asceta que se desprende de sus sensaciones y de sus pensamientos para salvar a lo incondicionado $(\mathrm{Paz}, 475)$

A mi entender, las oraciones ejemplificadas en (11) cumplen la función pragmática o discursiva que Hannay (1985: 175) llama Presentativa 1, puesto que no existe un fondo o contexto común entre hablante y oyente, por lo que debe construirse en el momento mismo de su enunciación. La expansión es el recurso idóneo para construir el contexto en estas oraciones.

Por otra parte, las oraciones existenciales expresadas con el resto de los predicados documentados en la muestra, e incluso con haber de manera esporádica cuando aparece pospuesto a la EE en oraciones como hay la necesidad de levantar el sureste de México, cumplen otra función, la que llamamos antes Presentativa 2, donde hablante y oyente comparten una referencia espacial o temporal común ya establecida en el contexto o en el discurso. De ahí que estas construcciones pueden no llevar referencias locativas explícitas, porque no las necesitan o porque son menos necesarias. El verbo haber parece invadir y participar, en ocasiones, de esta función pragmática, por ser el existencial más frecuente y por ello también el más flexible o el menos marcado de esta clase verbal. De acuerdo con lo anterior, podríamos clasificar los verbos existenciales en dos tipos, tal como se muestra en el esquema 1.

ciencia. Por el contrario, en inglés, el fenómeno es a la inversa, puesto que una tendencia actual es la pérdida de concordancia entre el verbo y la EE (Breivik 1997, S. Schwenter, comunicación personal). Ello se explica porque, en ese caso, la entidad topical es there, gramaticalizada a partir de una forma adverbial. En estas estructuras no parece relevante conservar la concordancia entre el verbo y la entidad existente, ya que la forma there que encabeza la oración, constituye la información conocida y anuncia que aparecerá después el foco de la predicación. 


\begin{abstract}
Haber
Función pragmática: foco o Presentativa 1

No hay nada previo a que aparezca el predicado. Al aparecer el verbo en el contexto, ello posibilita que se construya el espacio y la situación discursiva completa, por eso habrá que posponer a la oración una serie de especificaciones o expansión que complete la situación discursiva.

Ser, estar, existir y otros (haber con menor frecuencia y solo en ciertas construcciones):

Función pragmática: tópico o Presentativa 2

El contexto puede estar previamente dado, o bien se construye a partir de las referencias locativas o temporales, en las que se sitúan las EE. En el momento en que aparecen, hablante y oyente tienen el espacio "construido", en el cual se insertan las construcciones y también las EE. Son, en este sentido, más locativas que las anteriores, aunque no por ello dejan de ser existenciales, en tanto que presentan entidades en el discurso; lo que cambia con respecto de las anteriores es el contexto discursivo (ground).
\end{abstract}

ESQUEMA 1. Tipos de predicación existencial a partir de su función informativa

\title{
5. CONCLUSIONES
}

A partir de los datos presentados, podemos afirmar que las oraciones existenciales desempeñan más de una función informativa, en contraposición con la afirmación contundente de que siempre presentan entidadades nuevas en el discurso.

Las características sintácticas de las EE y también de las oraciones analizadas confirman que los verbos existenciales, y con mayor frecuencia el verbo prototípico haber, también introducen información conocida en algún sentido o de manera parcial y que en esos casos el único argumento verbal es el tópico y no el foco de la predicación. Así, a partir de las diferencias citadas, se advierte la existencia de dos funciones informativas distintas de las oraciones existenciales, descritas en el último apartado.

Hemos visto que, mientras el verbo existencial haber participa de las dos funciones, se usa con mayor frecuencia para introducir entidades focales y también que, en general, se usan otros verbos con valor existencial para presentar entidades que con menor frecuencia son el foco de la predicación, pues funcionan mayormente como tópico.

Esta explicación contribuye a la construcción, delimitación y descripción de la clase formada por los verbos existenciales en español, así como a la alternancia de sus miembros, pues sus frecuencias de uso se relacionan, sin duda, con las tareas semánticas y discursivas específicas de cada uno. El análisis presentado explica también, al menos en algunos aspectos, por qué el verbo haber es el existencial de uso más frecuente: porque ha participado de diversos procesos de gramaticalización que han desgastado su contenido semántico, tal 
como ocurre cuando sirve como elemento topical en la expresión de la existencia en oraciones que introducen información nueva en discurso.

\section{BIBLIOGRAFÍA}

Corpus básico (en orden cronológico)

Calila $(1250)$ = ANÓNIMO, Calila e Dimna, edición de Juan Manuel Cacho Blecua y María Jesús Lacarra, Madrid, Castalia, 1987.

GEII (1260-1280) = ALFONSO X, General estoria. Segunda parte, edición de Antonio G. Solalinde, Lloyd A. Kasten y Victor R. B. Oelschläger, 2 volúmenes, Madrid, Consejo Superior de Investigaciones Científicas, 1957.

DLE (según documento) = RAMÓN MENÉNDEZ PIDAL, Documentos lingüísticos de España . Reino de Castilla, Madrid, Consejo Superior de Investigaciones Científicas, 1966.

Celestina (1499) = FERNANDO DE ROJAS, La Celestina, edición de Dorothy S. Severin, Madrid, Cátedra, 1993.

CRC (1490) = HERNANDO DEL PUlgaR, Crónica de los Reyes Católicos, volumen 2, Guerra de Granada, edición de Juan de Mata Carriazo, Madrid, Espasa Calpe, 1940.

DLNE (según documento) = CONCEPCIÓN COMPANY COMPANY, Documentos lingüísticos de la Nueva España. Altiplano central, México, Universidad Nacional Autónoma de México, 1994.

Jovellanos (1780) = GASPAR MELCHOR DE JOVELLANOS, Obras en prosa, edición de José Caso González, Madrid, Castalia, 1969.

Villaorroel (1743-1758) = DIEGO DE TORRES VILLARROEL, Vida, ascendencia, nacimiento, crianzas y aventuras, edición de Guy Mercader, Madrid, Castalia, 1972.

Paz (1996) = OCTAVIO PAZ, "Vislumbres de la India", en Ideas y costumbres II. Usos y símbolos. Obras completas edición del autor, México, Fondo de Cultura Económica, pp. 355-487.

Marías (1998) = JAVIER MARÍAS, Negra espalda del tiempo, Madrid, Alfaguara.

Sentencia (2004) = Diario Oficial, Sentencia y votos de minoría particulares y aclaratorios relativos a la Acción de Inconstitucionalidad 14/2004 y sus acumuladas 14/2004 y 16/2004, promovidas por los partidos políticos Convergencia, Acción Nacional y de la Revolución Democrática, en contra del Congreso y del Gobernador Constitucional, ambos del Estado de Quintana Roo, lunes 4 de octubre de 2004, versión electrónica.

CREA (según ejemplo) = REAL ACADEMIA ESPAÑOLA, Banco de datos (CREA) [en línea]. Corpus de referencia del español actual. <http://www.rae.es $>$.

Corpus complementario

Cid $($ circa 1140) = ANÓNIMO, Cantar de mio Cid. Texto, gramática y vocabulario, edición paleográfica de Ramón Menéndez Pidal, volumen 3, Madrid, Espasa Calpe, 1944-1945. 
Setenario (1221-1284) = ALFONSO X, Setenario, edición de Kenneth H. Vanderford, Barcelona, Crítica, 1984.

Crónica general (1260-1280) = ALFONSO X, Primera crónica general de España, edición de Ramón Menéndez Pidal, Madrid, Gredos, 1955.

CORDE (según ejemplo) = REAL ACADEMIA ESPAÑOLA, Banco de datos (CREA) [en línea]. Corpus diacrónico del español. <http://www.rae.es>.

\section{Referencias bibliográficas}

Аввотт, В. (1992), “Definiteness, existentials and the 'list' interpretation”, en Proceedings of SALT II, Barker, C. y Dowty, D. (eds.), Columbus, Oh., Ohio State University, 1-16.

Аввотт, B. (1997), “Definiteness and existentials", Language, 73:1, 104-108.

ARIEL, M. (1988), "Referring and accessibility", Linguistics, 24, 65-87.

ARIEL, M. (1990), Accessing noun-phrase antecedents, London/New York, Routledge.

Bentivoglio, P. (1993), "Full NPs spoken Spanish: a discourse profile", en Linguistic perspectives on the romance languages (LSRL XXI), Ashby, W. J., M. Mithun, G. Perissinoto y E. Raposo (eds.), Amsterdam/Philadelphia, John Benjamins, 212224.

Bentivoglio, P. y SedAnO M. (1989), “Haber: ¿un verbo impersonal? Un estudio sobre el español de Caracas", en Estudios sobre español de América y lingüística afroamericana, Bogotá, Publicaciones del Instituto Caro y Cuervo, 59-81.

BIRNER, B.J. (2006), "Inferential relations and noncanonical word order", en Drawing the boundaries of meaning, Birner, B. J. y Ward, G. (eds.), Amsterdam/Philadelphia, John Benjamins, 31-51.

BIRNER, B.J. y WARD, G. (1993), “There-sentences and inversion as distinct constructions: a functional account", en Proceedings of the Annual Meeting of the Berkeley Linguistic Society 19, Berkeley, Berkeley University Press, 27-39.

BREIVIK, L.E. (1983), Existential there. A synchronic and diachronic study, Norway, The Norweigan Research Council for Science and the Humanities/University of Bergen.

BREIVIK, L.E. (1997), "There in space and time”, en Language in time and space, Ramisch, H. y Wynne, K. (eds.), Stuttgart, Franz Steiner Verlag, 32-45.

BREIVIK, L.E. (2003), “On relative clauses and locative expressions in English existential sentences", Pragmatics, 13:2, 211-230.

CHRISTOPHERSEN, P. (1939), The articles: a study of their theory and use in English, Copenague, Einar Munksgaard.

COMPANY COMPANY. C. (2006), “Tiempos futuros de formación romance II. Los futuros y condicionales", en Sintaxis histórica de la lengua española. Primera parte: La frase verbal. Volumen 1, Company, C. (dir.), México, Universidad Nacional Autónoma de México/Fondo de Cultura Económica, 347-418.

COROMINAS, J. (1980), Diccionario crítico etimológico castellano e hispánico, con la colaboración de José A. Pascual, 6 vols., Madrid, Gredos.

DAVIDSE, K. (1999), “The semantic of cardinal versus enumerative existential constructions", Cognitive Linguistics, 10:3, 203-250.

GARACHANA, M. (1994), El proceso de sustitución de aver por tener en el siglo XV, tesina de licenciatura inédita, Barcelona, Universidad de Barcelona. 
GARACHANA, M. (1997), “Acerca de los condicionamientos cognitivos y lingüísticos de la sustitución de aver por tener", Verba, 24, 203-235.

GARCía ROMERO, S. (2003), Los términos de elección libre en español: el caso de cualquier(a), tesis de doctorado inédita, Barcelona, Universitat Autònoma de Barcelona.

GIVÓN, T. (1983a), "Topic continuity in discourse: an introduction", en Topic continuity in discourse: a quantitative cross-language study, Givón, T. (ed.), Amsterdam/Philadelphia, John Benjamins, 5-41.

GIVÓN, T. (1983b), “Topic continuity in spoken English", en Topic continuity in discourse: a quantitative cross-language study, Givón, T. (ed.), Amsterdam/Philadelphia: John Benjamins, 343-363.

GOLDBERG, A.E. (1995), Constructions. A construction grammar approach to argument structure, Chicago/London, The University of Chicago Press.

GOLDBERG, A.E. (2006), Constructions at work. The nature of generalization in language, New York, Oxford University Press.

HANNAY, M. (1985), English existentials in functional grammar, DordrechtHolland/Cinnaminson-USA, Foris Publications, (Functional Grammar Series, 3).

HERNÁNDEZ DíAZ, A. (2003), “La semántica locativa de las construcciones existenciales con haber. Un ejemplo de gramaticalización", Medievalia 35. Gramaticalización y cambio sintáctico en la historia del español. Número monográfico, 135-154.

HERNÁNDEZ DÍAZ, A. (2004), “El verbo haber existencial en el español: ¿verbo inacusativo?", en VII Encuentro Internacional de Lingüística en el Noroeste. Memorias. Tomo 2, México, Universidad de Sonora, 125-141.

HERNÁNDEZ DÍAZ, A. (2006a), "Posesión y existencia. La competencia de haber y tener en la posesión y haber existencial", en Sintaxis histórica del español. Primera parte: La frase verbal. Volumen 2, Company, C. (dir.), México, Universidad Nacional Autónoma de México/Fondo de Cultura Económica, 1053-1160.

HERNÁNDEZ DÍAZ, A. (2006b), “Gramaticalización y reanálisis. La concordancia del verbo "haber" existencial en la diacronía del español", Actas del VI Congreso Internacional de Historia de la Lengua Española. Volumen I, Madrid, Arco Libros, 799-811.

HERNÁNDEZ DÍAZ, A. (2007a), Las construcciones existenciales en el español. Estructura y diacronía, tesis de doctorado inédita, México, Universidad Nacional Autónoma de México.

HERNÁNDEZ DÍAZ, A. (2007b), "De la posesión a la existencia en el español medieval", en Medievalia 39, 31-39.

LACA, B. (1996), “Acerca de la semántica de los 'plurales escuetos' en español”, en El sustantivo sin determinación, Bosque, I. (ed.), Madrid, Visor, 241-268.

LuMSDEN, M. (1988), Existential sentences. Their structure and meaning, New York, Croom Helm/Methuen.

LYONS, C. (1999), Definiteness, Cambridge, Cambridge University Press.

LYONS, J. (1975), "Deixis as the source of reference", en Formal semantics of natural language, Keenan, E. (ed.), London-New York, Cambridge, Cambridge University Press, 61-83.

Miguel, R. DE. (189711/2003), Nuevo diccionario latino-español etimológico, Madrid, Visor.

MiLSARK, G.L. (1979), Existential sentences in English, New York, Garland Publishing. 
PRINCE, E.F. (1981), “Toward a taxonomy of given-new information", en Radical Pragmatics, Cole, P. (ed.), New York, Academic Press, 223-255.

PRINCE, E.F. (1992), “The ZPG letter: subjects, definiteness, and information-status”, en Discourse description: diverse linguistic analyses of a fund-raising text, Mann, W. C. y Thompson, S. A. (ed.), Amsterdam/Philadelphia, John Benjamins, 295-325.

REAl ACADEMIA EsPaÑola (1732/1984), Diccionario de autoridades. Edición facsímil de la original de 1732, tres tomos, Madrid, Gredos.

REAl ACADEMIA ESPAÑola (2009), Nueva gramática de la lengua española, Madrid, Espasa Libros.

RIGAU, G. (1994), "Catalan presentational sentences and the properties of Agr nodes", en Paths towards universal grammar: studies in honor of Richard S. Kayne, Cinque, G., J. Koster, J.-Y. Pollock, L. Rizzi y R. Zanuttini (eds.), Washington, Georgetown University Press, 343-359.

ROMANI, P. (2006), “Tiempos de formación romance I. Los tiempos compuestos", en Sintaxis histórica de la lengua española. Primera parte: La frase verbal. Volumen 1, Company, C. (dir.), México, Universidad Nacional Autónoma de México/Fondo de Cultura Económica, 241-346.

SUÑER, M. (1982), Syntax and semantics of Spanish presentational sentence-types, Washington, D. C., Georgetown University Press. 